\section{LA GIMNÁSTICA COMO DISPOSITIVO ANTIONANISTA EN LA CONFORMACIÓN DE LA EDUCACIÓN FÍSICA ESCOLAR EN EL SIGLO XIX EN ESPAÑA: RECEPCIÓN DEL DISCURSO}

\author{
GYMNASTICS AS AN ANTI-ONANISTIC TOOL IN SHAPING SCHOOL PHYSICAL \\ EDUCATION IN 19TH CENTURY SPAIN: DISCOURSE RECEPTION
}

\section{A GINÁSTICA COMO DISPOSITIVO ANTIONANISTA NA CONFORMAÇÃO DA EDUCAÇÃO FÍSICA ESCOLAR DO SÉCULO XIX NA ESPANHA: RECEPÇÃO DO DISCURSO.}

\author{
Miguel Vicente-Pedraz ${ }^{*}$, Xavier Torrebadella-Flix*
}

Palabras clave: Salud escolar. Masturbación. Gimnasia. Historia del siglo XIX.

Keywords: School health Masturbation. Gymnastics. History, 19th century.

\begin{abstract}
Resumen: Los discursos higiénicos sanitarios del siglo XIX hicieron de la masturbación una enfermedad cuyos efectos se relacionaron desde muy pronto con la degeneración social. Algunos estudios han puesto en relieve esta relación como condicionante de las ideas pedagógicas al destacar la importancia de la gimnástica como práctica antionanista para la infancia. No obstante, ninguna investigación ha considerado la trascendencia de dicha práctica como dispositivo en la conformación de la educación física escolar. Este artículo es parte de una investigación genealógica más amplia sobre la influencia de la cruzada antionanista en la institucionalización de la educación física en la España del siglo XIX.
\end{abstract}

\begin{abstract}
Nineteen-century hygienist-health discourses referred to masturbation as an illness whose effects were related to social degeneration since early life. Some studies have highlighted that relation as a factor that conditioned pedagogic ideas by pointing out gymnastics' popularity as an anti-onanistic practice in childhood. However, no research has considered the importance of that practice as an instrument in the shaping of school Physical Education. This article is based on a more extensive genealogical research about the anti-onanist crusade influence in the institutionalization of Physical Education in Spain during the nineteenth century. The article is part of broader genealogical research about the anti-onanistic crusade in institutionalization of Physical Education in nineteencentury Spain
\end{abstract}

Resumo: $O$ discurso médico do século XIX fez da masturbação uma doença cujos

Palavras chave: Saúde escolar. Masturbação. Ginástica. História do século XIX. efeitos foram associados muito cedo com a degeneração social. Alguns estudos têm destacado essa relação como uma condição das ideias pedagógicas, enfatizando a importância da ginástica como prática antionanista para crianças. No entanto, nenhuma pesquisa considerou a importância dessa prática como um dispositivo para a formação da Educação Física Escolar. Este artigo é parte de uma pesquisa genealógica mais ampla sobre a influência da cruzada antionanista na institucionalização da Educação Física no século XIX na Espanha. Nele, podemos descrever e analisar a recepção da ideologia educacional da Europa central e do sul.
*Universidad de León. España. León, España.

E-mail:mvicp@unileon.es

**Universidad de Barcelona. Barcelona. España.

E-mail: xtorreba@gmail.com

Recebido em: 05-03-2015

Aprovado em: 20-08-2015

(c) (1) (8) Licence 


\section{INTRODUCCIÓN: MARCO TEÓRICO, PLANTEAMIENTO DEL PROBLEMA Y METODOLOGÍA}

La mayor parte de los estudios que se han interesado por los orígenes de la educación física escolar han tratado de determinar su conformación como disciplina considerando ciertas selectivas filiaciones pedagógicas, higiénicas, militares y morales de sus contenidos y de sus métodos. Fruto de una visión evolutiva, unidireccional y sistémica de estos, la historización predominante de la materia ha estado mayoritariamente orientada a la justificación de su presencia en la escuela a partir de una descripción parcial de acontecimientos y documentos, de acuerdo con lo que Popkewitz (2003, p. 146) denomina fantasía de orígenes -es decir, seleccionando del origen lo que concuerda con las justificaciones dominantes en el presente-. A este respecto, especialmente hasta mediados de los años noventa, han faltado explicaciones congruentes con un marco de análisis historiográfico plausible más allá de la selección historicista de los datos disponibles (ARÓSTEGUI SANCHEZ, 1995, LE GOFF, 1991, TOPOLSKY, 1992, WHITE, 1992). De tal modo es así que el material historiográfico al uso, incurriendo en lo que Norbert Elias (1990) denominaba sustancialismo evolucionista, ha venido a señalar que los ingredientes de la disciplinarización de la educación física fueron la sistematización y la racionalización del ejercicio físico; este, considerado como algo intrínseco a la naturaleza humana, habría sufrido un paulatino perfeccionamiento técnico y un constante ajuste funcional que desembocaría -casi como un precipitado natural, a finales del siglo XIXen la institucionalización escolar de la educación física.

Frente a ello, la historiografía crítica de la educación física -sobre todo la de corte constructivista y sociogenético, pone el acento en la relaciones dialécticas (y de poder) sobre las que se construye el orden de los conceptos y las prácticas dando lugar a un enfoque genealógico cuyas explicaciones admiten la discontinuidad, la ruptura, el cambio, las vías muertas, el azar, etc. lejos de la ordenación evolutiva de los acontecimientos, como si estos tuvieran un fin preestablecido (POPKEWITZ, 2003, VARELA, 2003, CUESTA FERNÁNDEZ, 2005). Particularmente, respecto de la configuración de los códigos disciplinares de la educación física, compromete el esfuerzo hacia el desvelamiento de las pugnas simbólicas, ideológicas y culturales libradas en torno a la construcción de las nociones de infancia, cuerpo, cuerpo apto y virtuoso, cuerpo sano, cuerpo educado, cuerpo viril, cuerpo reproductor, etc. -así como de los procesos de legitimación de las prácticas que les fueron dando sentido-, lo cual sitúa la educación física escolar en el campo de estudio interdisciplinar de las tecnologías de la gobernación y, más propiamente, de la biopolítica. A este respecto, algunos estudios existentes permiten explorar los procesos de configuración de la gimnástica, y en su caso de la educación física, en tanto que dispositivos de control disciplinario; como dispositivos del buen encauzamiento, oportunamente legitimados mediante discursos que apelaban desde la moral y la decencia hasta el fortalecimiento de la raza, durante siglo XIX (FLANDRIN, 1984, LAQUEUR, 2007, VÁZQUEZ GARCÍA; MORENO MENGÍBAR, 1996, VÁZQUEZ GARCÍA; SEOANE CEGARRA, 2004, VIGARELLO, 2005), o ya en el siglo XX con argumentos de carácter psicologicista más acordes con la moral académica del momento (WALKERDINE, 1995).

Con esta perspectiva, nuestro propósito es contribuir al desvelamiento de una de las pugnas más activas, y a la vez más silenciadas, en el contexto de la configuración de la educación física escolar en la España decimonónica: la pugna por la definición del cuerpo sexualmente ordenado. Teniendo en cuenta la concurrencia entre los valores puritanos en 
auge y los valores de lo que luego sería uno de los pilares curriculares de la educación física, el deporte, no sorprende el beneplácito que los apólogos de la moral victoriana, y particularmente los defensores del refreno ascético (TURNER, 1989), dispensaron al ejercicio físico como medida preventiva ante lo que la burguesía biempensante consideraba las peores corrupciones sexuales: la homosexualidad, el apoltronamiento corporal, el afeminamiento de los jóvenes y, singularmente, la masturbación (WATSON; WEIR; FRIEND, 2005). El modelo educativo que inspiró dicho beneplácito se extendió con relativa rapidez por el área de influencia británica en Norteamérica y también por la Europa continental. Particularmente, según Dupaux (2010), se extendió por Francia donde a principios del siglo XIX la masturbación aparecía como el principal problema al que debía responder la educación física (FRIEDLANDER, 1815) y, todavía en los estertores de dicha centuria, Pierre de Coubertin lo contemplaba como parte de su ideario pedagógico-deportivo (BARBERO GONZÁLEZ, 1990, CERCÓS RAICHS, 2010). Es de notar, asimismo, la importante difusión de parecidos planteamientos entre algunos destacados ideólogos alemanes como Salzman o Bassedow algunos de cuyos tratados pedagógicos y gimnásticos también harían acopio de los ideales morales y físicos en contra del onanismo. Argumentos similares se pueden encontrar incluso en Kant, particularmente en las disertaciones pedagógicas que, bajo la influencia roussoniana, dictó en la Universidad de Königsberg y que se publicaron en 1803 bajo el título de Pedagogía (Kant, 2003).

En España, aunque la prescripción de gimnástica como práctica preventiva y terapéutica contra la masturbación fue asumida tanto por la clase médica como por quienes ostentaban puestos de relevancia en la dirección moral y educativa del país, no ha habido estudios, salvo una advertencia de José Benito Seoane Cegarra (2008), que hayan puesto de relieve y analizado el papel que jugó en el proceso de conformación de la educación física. Partiendo de esta anotación y del estudio de una amplia documentación higiénico-pedagógica y médica de la época (TORREBADELLA FLIX, 2011), nuestra hipótesis es que la concepción del ejercicio físico como práctica antionanista, así como el modelo de disciplinamiento y normalización sexual en el que se configura, lejos de ser un aspecto marginal en el proceso de institucionalización de la educación física, fue un dispositivo determinante de su configuración como disciplina escolar; una configuración cuya legitimación, no obstante, sería tributaria de un largo proceso de pugnas ideológicas y culturales en torno a la categoría de cuerpo educado.

Para el desarrollo de la investigación hemos aplicado una metodología interpretativa y comparativa mediante las técnicas propias del análisis del discurso ideológico y del análisis del contenido de las fuentes directas a nuestra disposición (VAN DIJK, 1996, PINTO MOLINA, 2002). Previo al análisis documental, propiamente dicho, se procedió a una selección de textos a partir de los repertorios temáticos realizados por Xavier Torrebadella (2011), así como la revisión de fuentes digitalizadas, principalmente de la hemeroteca de la Biblioteca Nacional Española y de Google Books. Particularmente relevante ha sido el cotejo de las fuentes españolas, tanto traducciones como originales, con el objeto de establecer las líneas de influencia llegadas desde Europa así como los elementos singulares de la lucha contra el onanismo en la conformación de la educación física escolar en España.

Para llevar a cabo dicho cotejo hemos partido no tanto de la consideración técnica y evolutiva de los contenidos, los métodos y los materiales escolares (en términos de racionalización y sistematización pedagógica del ejercicio físico) como de una consideración dialéctica del proceso de configuración de la institución físico-educativa (en términos de pugnas 
simbólicas y de poder). Es decir, entendemos que la configuración de la institución físicoeducativa tuvo que ver, sobre todo, con los eventuales desenlaces de las confrontaciones culturales, morales e ideológicas en el campo de la definición de la subjetividad y su control.

\section{ANTECEDENTES EUROPEOS DE LA OFENSIVA ANTIONANISTA}

Señala Norbert Elias que toda investigación retrospectiva tiene que fijarse límites que se correspondan con las fases del proceso real puesto que no es operativo retrotraernos infinitamente en un proceso que carece de comienzo (ELIAS, 1988). Aunque las relaciones entre el orden físico y el moral - fijadas con el propósito de establecer el control de la conducta -, se remontan a la Antigüedad, el objetivo limitado de nuestro análisis nos induce a fijar el límite anterior en la divulgación de la obra de Samuel Auguste Tissot (1728-1797), cuya figura representa de manera proverbial el ideario ilustrado con sus luces (libertarias) y con sus sombras (disciplinarias). Si bien en Aviso a los literatos y a las personas de vida sedentaria sobre la salud (1771) advertía de que la primera ley que había que considerar era la salud del pueblo, su mayor fama se debió a las desmedidas argumentaciones sobre los males de la masturbación plasmadas en L'onanisme (1760) y cuya impronta en el pensamiento higiénicomédico y pedagógico tardó muchas décadas en ser desautorizada (LAQUEUR, 2007, VARELA; ÁLVAREZ-URÍA, 1986).

Recurre a ellas Rousseau, quien se refería a la masturbación como "un peligroso suplemento" (ROUSSEAU, 1821, p. 120) o, como hemos señalado, Kant, de manera muy explícita cuando señalaba que:

A los trece o catorce años es ordinariamente el momento en que se desenvuelve en el adolescente la inclinación sexual (cuando sucede más temprano es por haberles seducido y perdido con los malos ejemplos). Su juicio (p. 90) ya desarrollado y de la naturaleza los ha preparado para la época en que se puede hablar de esto.

Nada debilita tanto al espíritu y el cuerpo del hombre como esa clase de voluptuosidad dirigida a sí mismo y en completa lucha contra la naturaleza humana. Pero tampoco hay que ocultársela al adolescente. Se le ha de presentar en su horror, y decirle que así se inutiliza para la propagación de la especie; que las fuerzas de su cuerpo marcharan directamente a su ruina; que contrae una temprana vejez; que sufre su espíritu, etc.

Esta instigación se suele evitar mediante una ocupación constantemente, por lo cual es preciso que no consagre al sueño y a la cama más tiempo de lo necesario. (KANT, 2003, p. 90-91).

También, como ya han citado varios autores (FOUCAULT, 2012a, TARCZYLO, 1983, VÁZQUEZ GARCÍA; MORENO MENGIBAR, 1996), las utilizaron algunos de los máximos representantes de la pedagogía alemana de la época como Bassedow, Campe, Salzmann, Guts Muths o Nachtegall en cuyas instituciones educativas - los Philantropina - tuvieron lugar los comienzos de la denominada gimnástica educativa y donde además se sentaron las bases de la pedagogía negra basada en el principio de obediencia absoluta a la autoridad (MILLER, 1985). Asimismo, respaldaría los argumentos de Tissot (1760) contra el onanismo el que es considerado padre de la higiene pública, el doctor Johan Peter Frank (1745-1821), quien conseguiría articular todo un discurso facultativo sobre el onanismo como enfermedad y, por lo tanto, como ámbito de intervención propio del médico. 
En efecto, en el contexto de la familia burguesa, el dominio médico - que empezaba a desplazar al que durante tanto tiempo había ejercido el sacerdote (DONZELOT, 1998 p. 172) -, consiguió hacer responsable del control de la lacra del onanismo a los progenitores, educadores y sirvientes. Unos y otros eran conminados a mantener una estrecha vigilancia de los juegos de los niños y las niñas, de su lenguaje, de lo que oían y veían, aunque muy pronto esta vigilancia se trasladó al ámbito institucional: colegios, hospitales, hospicios, cuarteles, ayuntamientos, etc. haciendo de la masturbación, de acuerdo con George Vigarello (2005), el símbolo de una multidimensional creencia en torno a la degeneración de la especie.

Por lo que se refiere al contexto español, la difusión de los argumentos de L'Onanisme fue relativamente tardía debido, en buena medida, según Perdiguero y González (1990), a los recelos de la Iglesia a que se debatiera abiertamente sobre cuestiones sexuales. No obstante, a partir de la primera edición en castellano, con el título de Enfermedades de nervios producidas por el abuso de los placeres del amor y los exceso del Onanismo (TISSOT, 1807), la obra sería reeditada hasta en cuatro ocasiones más - 1814, 1828, 1845 y 1877- (VÁZQUEZ GARCÍA; MORENO MENGÍBAR, 1997). Que la obra de Tissot fuera objeto de interés editorial en las postrimerías del siglo XIX - más de un siglo después de su publicación original -, permite inferir hasta qué punto los principios del higienismo liberal habían impregnado el pensamiento médico. A pesar de los cambios sociales y culturales experimentados a lo largo de la centuria y, particularmente, a pesar de los avances científicos en el ámbito de la teoría y la praxis médica, el interés normalizador continuaba inspirando a los moralistas españoles ya fuera que provinieran del campo de la educación o de la medicina.

\section{RECEPCIÓN Y TRADUCCIÓN DE LOS POSTULADOS ANTIONANISTAS}

Los discursos y las prácticas fundacionales de la gimnasia como dispositivo antionanista en España no siguen un decurso lineal y continuo sino que, más bien, se construyen por recepción e irradiación, avance y retroceso, acumulación y sustracción; un proceso que se inscribe, no obstante, en la dinámica de transformaciones propias de los estados liberales del siglo XIX: parten del interés por el encauzamiento disciplinario de los sujetos (de carácter anatomopolítico) para configurarse paulatinamente como estrategias de control poblacional (de carácter biopolítico). Para el caso concreto que nos ocupa - la configuración de la gimnasia higiénica y ulteriormente la gimnasia educativa - se puede decir que los distintos discursos y prácticas que conformaron la cruzada antionanista, aunque cada uno de ellos respondía, parafraseando a Foucault (2012b), a exigencias de coyuntura, en su conjunto acabaron definiendo cierto modo de adscripción política y detallada del cuerpo; terminaron por dar forma a la educación física escolar en tanto que dispositivo (microfísico) de encauzamiento de la conducta: una variante, según Miguel Vicente Pedraz (2001), de las actuaciones administrativas y políticas que la modernidad urbana aplicó al arte de gobernar el cuerpo; una variante cuyos antecedentes disciplinares y disciplinarios se pueden encontrar, según Vicente Pedraz y Brozas Polo (2014), en la obra de Josefa Amar y Borbón, el Discurso sobre la educación física y moral de las mujeres de 1790 (AMAR Y BORBÓN, 1790).

En todo caso, en un proceso de aproximadamente un siglo de duración cabe distinguir a efectos expositivos dos periodos. El primero se corresponde con la etapa de conformación del higienismo liberal en España - primera mitad del siglo XIX -, definido por la recepción y 
traducción de obras europeas, mientras que el segundo abarcaría desde mediados de los años cuarenta hasta finales de siglo, siendo un periodo caracterizado por la producción propia aunque, evidentemente, esta se alimentara de los discursos que seguían llegando del exterior y permeando la opinión de médicos y pedagogos.

Respecto del primer periodo, objeto específico de este artículo ${ }^{1}$, es preciso tener en cuenta los elementos condicionantes del pensamiento médico liberal de la época. Este, heredero directo del optimismo ilustrado, se configuró en torno a la búsqueda del orden moral y físico, de la estabilidad social y económica, mediante acciones de control sanitario (de carácter formativo, coercitivo, purgante, punitivo, etc.) que por entonces empezaba a aplicarse a escala individual de forma privada o en el seno familiar. Las políticas higienistas se correspondían con el tipo de acciones de carácter filantrópico, caritativo, eclesiástico, vecinal, etc. no gubernamentales - como le era propio a los Estados liberales de la primera mitad del siglo XVIII - inscritas en lo que Foucault consideraba anatomía política en su análisis del biopoder (VÁZQUEZ GARCÍA; SEOANE CEGARRA, 2004).

En este contexto, a la difusión de las preocupaciones y los preceptos para cauterizar el que, desde muy pronto, se consideró un mal de la juventud española contribuiría, además de la propia obra de Tissot, la traducción de obras como La gimnástica o escuela de la juventud del alemán Salzmann quien señalaba que su "[...] principal objeto es proteger la fuerza moral desenvolviendo y aumentando la física por medio de ejercicios continuados". (AMAR; JAUFFRET, 1807, p. 258). No obstante, la más poderosa influencia la ejercería el higienismo francés a través de las obras traducidas al castellano de Bégin (1822), Londe (1829), Deslandes 1830), Doussin-Dubrenil (1831), Jullien (1840), Foy (1845), Broussais (1846) o Lévy (1846), entre algunas otras.

Todas ellas eran deudoras de los postulados de Tissot y algunas directamente vinculadas al incipiente movimiento gimnástico hispano-francés fundado por Francisco de Amorós, un valenciano afincado en París, autor del emblemático Manuel d'education physique, gymnastique et moral (AMOROS, 1830).

Así, por ejemplo, Luis Jacques Bégin, médico del Hospital de Metz y colaborador de Amorós señalaba que:

[...] el objeto de la educación física y de la gimnástica médica, es proporcionar la destrucción de un temperamento poco favorable, corregir una idiosincrasia viciosa y hacer que les sucedan estados más provechosos (BÉGIN, 1822, p. 18-19).

Asimismo, según recoge Losada, Bégín advertía de que en la adolescencia era cuando más había que incidir para contrarrestar la masturbación:

Los medios más adecuados para prevenir o para corregir el funesto abuso de la masturbación, consisten en llenar las acciones vitales hacia el exterior por medio de ejercicios bien dirigidos, por una gimnasia racional (DICCIONARIO..., 1838, p. 384).

De manera parecida, Carlos Londe, cuya obra Nuevos elementos de Higiene fue editada en castellano en 1829 acentuaba la influencia general que sobre el organismo tenían los ejercicios corporales activos - andar, baile, carrera, saltos, caza, esgrima, ejercicios gimnásticos, etc.-, los pasivos - carruaje y navegación - y los mixtos -equitación - debiendo 
prestar atención, señalaba, a las edades y el sexo. Londe, que elogió la obra y el gimnasio de Amorós, no eludió el controvertido asunto de la educación doméstica y pública para "[...] remediar la actividad excesiva del apetito venéreo". (LONDE, 1829, p. 103); a este respecto, para frenar el apetito sexual, recomendaba el ejercicio activo todos los días y para corregir el vicio contraído de la masturbación estipulaba que al joven: "[...] se le deberá habituar cuando pueda y hasta el cansancio, al ejercicio de las armas, de la lucha y de la pelota, a los cuales se agregará un verano a la natación, tres veces al día poco más o menos (LONDE, 1829, p. 104-105).

Marc Antoine Jullien (1775-1848) en el apéndice III de su Ensayo general de educación física, moral e intelectual (1840) se refería a dos informes propósito de la gimnástica práctica y su relación con los ejercicios del Gimnasio normal, civil y militar de Francisco Amorós. En él describía la importancia de la educación física en la educación general, la cual debía ser integral, y sobre todo la conveniencia que tenía para la formación de los jóvenes y la sociedad. Pues bien, Jullien, que presentaba el gimnasio amorosiano como un ejemplo a seguir, señalaba que "[...] el objeto de la gimnástica es el de conservar la salud favoreciendo el desarrollo de todas las facultades físicas y morales" (JULLIEN 1840, p. 394), siendo el establecimiento del señor Amorós, por su buena dirección, el que mejor podía ofrecer estos felices resultados:

Con la gimnástica es con lo que se obtiene el precaver y destruir los hábitos viciosos dimanados del exceso de sensibilidad de los órganos de la generación. Las amenazas, los castigos y otras medidas adoptadas, no han podido hasta ahora impedir el onanismo. La gimnástica, digámoslo francamente, suministra los únicos medios eficaces contra este funesto hábito. El señor Amorós ha obtenido ya sin esfuerzos un gran número de curaciones de este género (JULLIEN, 1840, p. 407).

En sentido parecido, Casimiro Broussais, hijo del que fuera mentor científico de Amorós - Victor Broussais -, recomendaba la lectura de los opúsculos de Amorós y reclamaba la introducción de la gimnástica en los colegios para prevenir lo que calificaba comotrastorno demasiado común de la juventud para el que ningún otro medio coercitivo era mejor que la gimnasia; así, en De la gimnástica considerada como medio terapéutico e higiénico, apuntaba:

La gimnastica es, sin contradicción, el medio más eficaz de cuantos puedan oponerse a los excesos de la masturbación, llamando las fuerzas al sistema muscular, impidiendo las concentraciones y destruyendo el exceso de irritabilidad del sistema nervioso, impone silencio a los órganos genitales y desvía el pensamiento de los goces que su excitación proporciona (BROUSSAIS, 1846, p. 314).

Aunque no vinculados directamente con Amorós y su obra, algunos otros autores, luego traducidos al castellano, se adscribieron a la cruzada gimnástica antionanista. Este es el caso de Antonio Deslandes, doctor en medicina, quien defendía el valor y la utilidad de la educación física especialmente para quienes, por su propensión linfática, corrían el peligro de caer en una vida ociosa y sedentaria:

Guárdense los padres de familia, si estiman la salud de sus hijos de ponerlos en estas casas de educación donde la educación física esta descuidada 0 despreciada; en donde los individuos destinados a trabajos útiles en lo sucesivo, se educan como si hubieran de venir a parar en un convento; que los coloquen en donde las prácticas minuciosas e inútiles no sustituyen los saludables ejercicios: colóquenles si pueden, en estas casas en donde la gimnástica reducida a un arte hace marchar de frente la educación del cuerpo con la del corazón y del espíritu (DESLANDES, 1830, p. 338-339). 
Caso aparte lo constituyen las referencias, ciertamente más infrecuentes, a la masturbación femenina aunque no faltan ejemplos al respecto. Entre quienes trataron el asunto cabe destacar a Doussin-Dubrenil en cuya obra Extravíos secretos o el onanismo en las personas del bello sexo indicaba algunos métodos o juegos mediante los que las niñas se abandonaban al placer, advirtiendo de los síntomas para detectar el hábito onanista e indicando algunos tratamientos para evitarlo:

Dos hermanas he conocido, la una de edad de seis años, y la otra de doce, las que habituadas a hacer equitación sobre cuerdas más o menos tirantes, se pusieron en poco tiempo tan débiles y enclenques que causaron inquietudes, tanto o más grandes, cuando no se sabía a qué atribuir su estado; una de ellas tenía ataques muy parecidos a los de la epilepsia (DOUSSIN-DUBRENIL, 1831, p.85-86).

Algunos años más tarde Doussin-Dubrenil (1840) publica Peligros del onanismo en los dos sexos y consejos relativos al tratamiento de las enfermedades que este vicio ocasiona que fue traducido y extensamente publicitado en la prensa. Uno de estos anuncios aconsejaba sobre la cuestión a los padres, a los directores de establecimientos de educación y a "los profesores del arte de curar": "El autor trata la materia tan delicada con la mayor circunspección y aprovecha todas las ocasiones de hacer algunas reflexiones morales muy útiles para atraer al sendero de la virtud la juventud extraviada". (ANUNCIO, 1840, p. 4).

En 1843 una nueva edición del Tratado de higiene Londe volvía a considerar que para alejar a los jóvenes de la masturbación eran recomendables:

La lucha, que estimula poderosamente el amor propio con el aliciente de una victoria debida a la fuerza y a la destreza reunidas, es por la misma razón, como la esgrima, un medio excelente de separar a los jóvenes reunidos en los colegios de los perniciosos hábitos a que se entregan con sobrada frecuencia en la época de la libertad. (LONDE, 1843, p. 349).

Por su parte, François Foy recomendaba los ejercicios gimnásticos como el mejor medio para eliminar el vicio de la masturbación y prescribía que había de someter a "[...] los masturbadores a ejercicios activos, variados y frecuentes, para que tengan necesidad de descanso" (FOY, 1845, p. 313).

A partir de 1846, el Tratado completo de higiene pública de Miguel Lévy (1809-1872), profesor de higiene y de medicina legal en el Hospital Militar de París, muy conocido en España, destacó la influencia que ejerció sobre la obra higiénica de Pedro Felipe Monlau (1846). Lévy pedía que en los asilos para la infancia, colegios y seminarios se contemplasen espacios al aire libre y estancias o patios para la realización de los ejercicios gimnásticos. En cuanto a los asuntos relacionados con la "educación y las costumbres" se ocupaba de lo que decía ser un mal endémico en la mayoría de colegios donde no había la costumbre de metodizar ejercicios gimnásticos diariamente. No es de extrañar que, en este sentido, Lévy, del mismo modo que Londe (1829), propusiera como medida correctiva la poderosa acción fisiológica y moral de la gimnástica. Anótese que, además, aconsejaba que la gimnástica formase parte de los concursos o exámenes públicos que solían hacer los colegios de buena reputación:

El problema de la educación es el equilibrio de las fuerzas físicas y de las facultades intelectuales; no puede obtenerse sino por medio de una gimnástica obligatoria, variada y adaptada a cada edad, alternada por intervalos iguales con los ejercicios de la inteligencia, honrada y recompensada en los concursos anuales lo mismo que los estudios literarios. Desde la invención de las armas de 
fuego, se han desconocido demasiado los efectos poderosos del ejercicio regular, habitual y enérgico; las ocupaciones variadas, la fatiga del cuerpo, el cultivo de la inteligencia, los principios morales y religiosos y una vigilancia continua, tales son los medios que es preciso oponer al onanismo en los establecimientos públicos; y son principalmente necesarios en los del otro sexo, porque las casas ortopédicas nos presentan a las niñas en una proporción de cinco sextas del total de pensionistas. (LÉVY, 1846, p. 244).

La cruzada higiénica contra el onanismo y el papel que en todo ello jugó la gimnástica como mecanismo coadyuvante - y a la vez como beneficiaria de las políticas disciplinariastraspasaría los límites temporales de la mitad de siglo. En un contexto de fuerte influencia científica e ideológica gala, sobre todo entre las clases acomodadas e ilustradas, siguieron traduciéndose obras procedentes del país vecino ${ }^{2}$, aunque las producciones higiénicogimnásticas domésticas contra el vicio de la masturbación no se harían esperar.

Uno de los primeros, y desde luego el más influyente higienista español de mediados del XIX, sería el médico barcelonés Pedro Felipe Monlau (1808-1871) cuyas obras, Elementos de higiene privada (1846) y Elementos de higiene pública (1847) alcanzarían amplia y prolongada resonancia (VARELA; ÁLVAREZ-URÍA, 1989). La obra de Monlau, desde luego, pertenece por tiempo y por ideología al higienismo liberal, sin embargo, ya contenía algunos elementos que anunciaban la ulterior mutación hacia los modelos sanitarios estatalizados propios de los estados intervencionistas, gubernamentalistas, de finales de siglo. No en vano en 1847, año de publicación de Elementos de higiene pública se crearía la Dirección General de Sanidad, órgano consultivo del Consejo de Sanidad que, como ha puesto de relieve Sánchez Granjel (1986), evidencia la pretensión de hacer efectivo el control gubernamental de la política sanitaria; una pretensión que desembocaría en la promulgación, ya en 1855, de la primera Ley de Sanidad española.

A este respecto, aunque Monlau ejemplifica la eclosión del higienismo liberal genuinamente español, también anuncia - tal vez debido a la recepción en esos momentos de nuevas ideas sanitarias desde Europa - un cambio en las políticas sanitarias y en la ideología sobre el control del cuerpo.

\section{A MODO DE CONCLUSIÓN}

Se ha puesto de relieve cómo a partir de L'onanisme de Tissot se fraguauna de las mayores contribuciones del pensamiento higiénico-médico del siglo XIX a la pedagogía moderna: la cruzada antionanista. La poderosa sugestión del discurso llegó a persuadir a importantes pensadores de la llustración, como Rousseau o Kant, quienes le dieron legitimidad y, con ello, curso a la educación burguesa liberal fuertemente impregnada por el reformismo puritano.

Aunque el antionanismo decimonónico presenta múltiples caras, se ha puesto énfasis en cómo las nuevas corrientes sanitarias utilizan laenfermedad paraexplicar los problemas higiénicos y sociales de la época y justificar el emprendimiento de medidas de control social; particularmente, medidas decontrol médico-moral sobre las familias y la población.

Lacruzada llegó a España por influencia francesa a partir del periodo liberal, momento significativo en proceso dela escolarización burguesa y del despliegue urbanístico e industrial de las principales ciudades del país.

2 Entre estas obras destacamos las de La Mert (1849), Teste (1850), Debreyne (1855), Descuret (1857), Baudouin (1866) y Seraine (1876). 
La cruzada antionanista tuvo en la naciente gimnástica un importante aliado en tanto que la fatiga físicas consideró desde muy pronto como un antídoto contra los impulsos autoeróticos; pero, asimismo, la gimnástica encontró en dicha cruzada el discurso perfecto para legitimarse como práctica biopolítica regular, entre disciplinaria y correctiva, entre disuasoria y normalizadora, en el seno de la escuela.

Tanto la práctica como los discursos que legitimaron la gimnástica irradiaron desde Centro Europa hacia el sur del continente y hacia el continente americano donde los defensores locales del ascetismo puritano elaborarían sus propios discursos, en consonancia con las particularidades de cada contexto, dando curso al proceso de institucionalización de la educación física escolar de finales del siglo XIX.

Conociendo la dificultad que supone el recopilar suficientes datos factuales que aborden la problemática histórica de la gimnástica como dispositivo antionanista, una vez analizada la recepción de los discursos de Centro Europa en España, en un próximo artículo presentamos la casuística según la cual la prescripción facultativa de la gimnástica como la política preventiva y terapéutica contra la masturbación infantil encontró en este país un entorno providencial para la elaboración de un discurso propio.

\section{REFERENCIAS}

ANUNCIO. El Eco del Comercio, Madrid: 12 de abril de 1840, p. 4.

AMAR, Jean-Agustin; JAUFFRET, Louis-François. La gimnástica o escuela de la juventud: tratado elemental de juegos, de ejercicios considerados en razón de su utilidad física y moral. Madrid: Álvarez, 1807.

AMAR Y BORBÓN, Josefa. Discurso sobre la educación física y moral de las mujeres. Madrid: Imprenta de Benito Cano, 1790.

AMOROS, Francisco. Manuel d'éducation physique, gymnastique et morale. Paris: Librairie Encyclopédique de Roret, 1830.

ARÓSTEGUI SÁNCHEZ, Julio. La investigación histórica: teoría y método. Barcelona: Crítica, 1995.

BARBERO GONZÁLEZ, José Ignacio. La aparición de los deportes en las "Public Shools" ¿Tomas Arnold o los Cristianos musculares? Perspectivas de la Actividad Física y el Deporte, León, n. 5, p. 34-36, 1990.

BAUDOUIN, Jean Magloire. La enseñanza primaria y especial en Alemania. Barcelona: Juan Bastinos, 1866.

BÉGIN, Louis-Jacques. Principios generales de fisiología-patológica. San Sebastián: Ignacio Ramón Baroja, 1822.

BROUSSAIS, Casimir. De la gimnástica considerada como medio terapéutico e higiénico. In: RECOPILACIÓN de los descubrimientos y progresos de las ciencias médicas. Madrid: D. M. Delgrás, 1846. p. 311-317, p. 386-394. 
BUSQUÉ TORRÓ, Sebastián. Gimnástica, higiénica, médica y ortopédica o el ejercicio considerado como medio terapéutico. Madrid: Manuel Galiano, 1865.

CERCÓS RAICHS, Raquel. El ideal del gentleman: una pedagogía de la masculinidad: la herencia del puritanismo victoriano. In: MOREU, Ángel C.; PRATS, Enric (Coord.). La educación revisitada: ensayos de hermenéutica pedagógica. Barcelona: Publicacions i Edicions de la Universitat de Barcelona, 2010. p. 185-307.

CUESTA FERNÁNDEZ, Raimundo. Felices y escolarizados: crítica de la escuela en la era del capitalismo. Barcelona: Octaedro, 2005.

DEBREYNE, Pierre Jean Corneille. Ensayo sobre teología moral considerándola en sus relaciones con la fisiología y la medicina. Barcelona: Pons, 1855.

DESCURET, Jean Baptiste Félix. La medicina de las pasiones. 2. ed. Barcelona: Pablo Riera, 1857.

DESLANDES, Leopoldo. Compendio de higiene pública y privada o tratado elemental de los conocimientos relativos a la conservación de la salud, y a la perfección física y moral de los hombres. Gerona: Oficina de A. Oliva, 1830. v. 2.

DICCIONARIO de medicina y de cirugía prácticas. Traducción de Felipe Losada. Madrid: Ignacio Boix, 1838. v. 1.

DONZELOT, Jacques. La policía de las familias. Valencia: Pre-textos, 1998.

DOUSSIN-DUBRENIL, Jacques-Louis.Extravíos secretos o el onanismo en las personas del bello sexo. Madrid: Pedro Sanz, 1831.

DUPAUX, Jean-Jacques. Les pratiques sportives alibis! Occuper l'imagination des jeunes

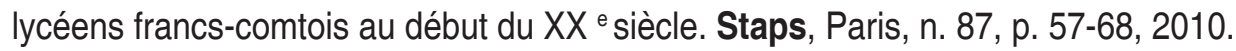

ELIAS, Norbert. El proceso de la civilización. Madrid: F.C.E., 1988.

ELIAS, Norbert. La sociedad de los individuos. Barcelona: Península, 1990.

FLANDRIN, Jean Louis. La moral sexual en occidente. Barcelona: Juan Granica, 1984.

FOUCAULT, Michel. Historia de la sexualidad I: la voluntad de saber. Madrid: Biblioteca Nueva, 2012a.

FOUCAULT, Michel. Vigilar y castigar: nacimiento de la prisión. Madrid: Biblioteca Nueva, 2012b.

FOY, François. Manual de higiene. Madrid: Ignacio Boix, 1845.

FRIEDLANDER, Michael. De l'éducation physique de l'homme. Paris: Treuttel et Würtz, 1815.

JULLIEN, Marc Antoine. Ensayo general de educación física, moral e intelectual. Valencia: Ventura Lluch, 1840.

KANT, Immanuel. Pedagogía. Madrid: Akal, 2003.

LA MERT, Samuel. La conservación personal: tratado interesante de las causas de la decadencia prematura de la energía física y mental y demás atributos de la virilidad,... 2. ed. Barcelona: Oliveres, 1849. 
LAQUEUR, Thomas. Sexo solitario: una historia cultural de la masturbación. Buenos Aires: Fondo de Cultura Económica, 2007.

LE GOFF, Jacques. Pensar la historia. Barcelona: Paidós, 1991.

LÉVY, Miguel. Tratado completo de higiene pública. Madrid:Viuda de Calleja, 1846.

LONDE, Carlos. Nuevos elementos de higiene. Madrid: Fuentenebro, 1829.

LONDE, Carlos. Tratado completo de higiene. Tomo I. Madrid: Viuda de Calleja e Hijos, 1843.

MILLER, Alice. Por tu propio bien: raíces de la violencia en la educación del niño. Barcelona: Tusquets, 1985.

MONLAU, Pedro Felipe. Elementos de higiene privada: 0 arte de conservar la salud del individuo. Madrid: Pablo Riera, 1846.

MONLAU, Pedro Felipe. Elementos de higiene pública. Barcelona: Pablo Riera, 1847.

PERDIGUERO GIL, Enrique; GONZÁLEZ DE PABLO, Ángel, Los valores morales de la higiene. El concepto de onanismo como enfermedad según Tissot y su tardía introducción en España. Dynamis Acta Hispánica ad Miedicinae Scientiarum Historiam Ilustrandam, Barcelona, $n$. 10, 131-162, 1990.

PINTO MOLINA, María. Análisis documental de contenido. In: LÓPEZ YEPES, José (Coord.). Manual de ciencias de la documentación. Madrid: Pirámide, 2002. p. 419-447.

POPKEWITZ, Thomas S. La producción de razón y poder: historia del currículo y tradiciones intelectuales. In: POPKEWITZ, Thomas S.; FRANKLIN, Barry M.; ÁNGEL, Miguel (Comp.). HISTORIA cultural y educación. Barcelona: Pomares, 2003. p. 146-184.

ROUSSEAU, Jean-Jacques. Emilio: o de la educación. Madrid: Alban, 1821. v. 2.

SÁNCHEZ GRANJEL, Luis, La medicina española contemporánea. Salamanca: Ediciones de la Universidad de Salamanca, 1986.

SEOANE CEGARRA, José Benito. Escuela, higiene y sexualidad infantil. In: MAINIER, Juan (Coord.). Pensar críticamente la educación escolar: perspectivas y controversias historiográficas. Zaragoza: Prensas Universitaria de Zaragoza, 2008. p. 229-254.

SERAINE, Louis. Higiene física y moral de los niños. Madrid: Álvarez Hermanos, 1876.

TARCZYLO, Théodore. Sex et liberté au siècle des lumières. Paris: Presses de la Renaissence, 1983.

TESTE, Alph. Tratado homeopático de las enfermedades agudas y crónicas de los niños. Toledo: Severiano López Fando, 1850.

TISSOT, Samuel Auguste D. Aviso a los literatos y a las personas de vida sedentaria sobre su salud. Zaragoza: Francisco Moreno, 1771.

TISSOT, Samuel Auguste D. Enfermedades de nervios producidas por el abuso de los placeres del amor y los excesos del Onanismo. Madrid: Imp. de la Calle Greda, 1807.

TISSOT, Samuel Auguste D. L'onanisme: ou dissertation physique sur les maladies produites par la masturbation. Laussanne: Chapuis, 1760. 
TOPOLSKY, Jerzy. Metodología de la historia. Madrid: Cátedra, 1992.

TORREBADELLA FLIX, Xavier. Repertorio bibliográfico inédito de la educación física y el deporte en España (1800-1939). Madrid: Fundación Universitaria Española, 2011.

TURNER, Bryan S. El cuerpo y la sociedad. México: Fondo de Cultura Económica, 1989.

VAN DIJK, Teun. A. Análisis del discurso ideológico. Versión, México, n. 6, p. 15-43, 1996.

VARELA, Julia. Conocimiento poder y subjetivación en las instituciones educativas. Sobre las potencialidades del método genealógico en el análisis de la educación formal e informal. In: POPKEWITZ, Thomas S.; FRANKLIN, Barry M.; ÁNGEL, Miguel (Comp.). Historia cultural y educación. Barcelona: Pomares, 2003. p. 127-145.

VARELA, Julia; ÁLVAREZ-URÍA, Fernando. Las redes de la psicología. Madrid: Libertarias, 1986.

VARELA, Julia; ÁLVAREZ-URÍA, Fernando. Sujetos frágiles. Madrid: Fondo de Cultura Económica, 1989.

VÁZQUEZ GARCÍA, Francisco; MORENO MENGÍBAR, Andrés. Genealogía de la educación sexual en España: de la pedagogía ilustrada a la crisis del estado del bienestar. Revista de Educación, Madrid, n. 309, p. 67-94, 1996.

VÁZQUEZ GARCÍA, Francisco; MORENO MENGÍBAR, Andrés. Sexo y razón: una genealogía de la moral sexual en España (Siglos XVI-XX). Móstoles: Akal, 1997.

VÁZQUEZ GARCÍA, Francisco; SEOANE CEGARRA, José Benito. España y la cruzada médica contra la masturbación (1800-1900). Elementos para una genealogía. Hispania, Madrid, n. 218, p. 835-868, 2004.

VICENTE PEDRAZ, Miguel.La mirada del otro: escuela, cuerpo y poder». Renovar la Teoría y la Práctica, Coruña, n. 84, p. 5-14, 2001.

VICENTE PEDRAZ, Miguel; BROZAS POLO, María Paz. El "Discurso sobre la educación física y moral de las mujeres" (1790) de Josefa Amar y Borbón: feminidad y el arte de gobernar el cuerpo en la llustración española. Movimento, Porto Alegre, v. 20, n. 2, p. 799-818, 2014.

VIGARELLO, Georges. Corregir el cuerpo: historia de un poder pedagógico. Buenos Aires: Nueva Visión, 2005.

WALKERDINE, Valerie. Psicología del desarrollo y pedagogía centrada en el niño. La inserción de Piaget en la educación temprana. In: LARROSA, Jordi. (Ed.). Escuela, poder y subjetivación. Madrid: La Piqueta, 1995. p. 79-54.

WATSON, Nick J.; WEIR, Stuart; FRIEND, Simon. The development of muscular Christianity in Victorian Britain and beyond. Journal of Religion and Society, Creighton, v. 7, n. 1, p. 1-25, 2005.

WHITE, Hayden. El contenido de la forma. Barcelona: Paidós, 1992. 